\title{
OБ30P / REVIEW
}

УДК 159.9.07 (606)

http://dx.doi.org/10.22328/2413-5747-2021-7-1-7-19

() Жиров В.К., Закревский Ю.Н., Гонтарь О.Б., Мегорский В.В., Койгерова А.А., Маурчева П.А., 2021 г.

\section{ЛАНДШАФТНАЯ ТЕРАПИЯ НАРУШЕНИЙ ЗРИТЕЛЬНЫХ ВОСПРИЯТИЙ НА КРАЙНЕМ СЕВЕРЕ}

\author{
${ }^{1,3}$ В. К. Жиров ${ }^{2}$ Ю. Н. Закревский, ${ }^{3}$ О. Б. Гонтарь, ${ }^{3}$ В. В. Мегорский, \\ ${ }^{4}$ А. А. Койгерова, ${ }^{1}$ П. А. Маурчева \\ ${ }^{1}$ Полярно-альпийский ботанический сад-институт имени Н. А. Аврорина, Кировск, Россия \\ ${ }^{2}$ Мурманский арктический государственный университет, Мурманск, Россия \\ ${ }^{3}$ Научный исследовательский центр медико-биологических проблем адаптации человека \\ в Арктике Федерального исследовательского центра «Кольский научный центр РАН», \\ Апатиты, Россия \\ ${ }^{4}$ Лаборатория медицинских и биологических технологий ФИЦ «Кольский научный центр РАН», \\ Апатиты, Россия
}

\begin{abstract}
Освоение российского арктического континентального шельфа с добычей больших объемов нефтепродуктов, продолжение функционирования известных горнорудных предприятий Кольского Севера по добыче необходимых для промышленности страны редкоземельных и цветных металлов, базирование Северного флота как важнейшей составляющей обороноспособности страны требуют хорошего состояния здоровья всех категорий работников и военнослужащих континентальной зоны и арктических островов на Крайнем Севере. Особое значение в этих условиях приобретают психоневрологические заболевания, в том числе связанные с нарушениями зрительного восприятия, развивающиеся на почве “синдрома полярного напряжения». По результатам обобщения существующих в научной литературе взглядов о целостности механизмов зрительного восприятия разработана двумерная классификация различных форм ее изменчивости, которая может использоваться в качестве методологической основы конструирования виртуальных и физических лечебных ландшафтов в рекреационных зонах отдыха военных объектов, ведомственных санаториях и домах отдыха в целях профилактики и лечения психоневрологических нарушений, вызванных ффункциональными нарушениями организма вследствие воздействия «полярной нагрузки» и длительным пребыванием в замкнутых технологических пространствах.

Ключевые слова: морская медицина, ландшафтная терапия, зрительное восприятие, замкнутые пространства, психоневрологические зрительные нарушения
\end{abstract}

*Контакт: Жиров Владимир Константинович, v_zhirov_1952@mail.ru

(c) Zhirov V.K., Zakrevsky Yu.N., Gontar O.B., Megorsky V.V., Koygerova A.A., Maurcheva P.A., 2021

\section{LANDSCAPE THERAPY FOR DISORDERS OF VISUAL PERCEPTION IN THE FAR NORTH}

${ }^{1,3}$ Vladimir K. Zhirov ${ }^{*},{ }^{2}$ Yury N. Zakrevsky, ${ }^{3}$ Oksana B. Gontar, ${ }^{3}$ Vladimir V. Megorsky,

${ }^{4}$ Alena A. Koygerova, ${ }^{1}$ Polina A. Maurcheva

${ }^{1}$ Polar Alpine Botanical Garden and Institute, Kirovsk, Russia

${ }^{2}$ Murmansk State Arctic University, Murmansk, Russia

${ }^{3}$ Research Center for Biomedical Problems of Human Adaptation in Arctic of the Federal

Research Center «Kola Scientific Center of Russian Academy of Sciences», Apatity, Russia

${ }^{4}$ Laboratory of Medical and biological technologies of the Federal Research Center «Kola Scientific

Center of Russian Academy of Sciences», Apatity, Russia

The development of the Russian Arctic continental shelf with the production of large volumes of oil products, the continuation of the functioning of the well-known mining enterprises of the Kola North for the extraction of rare earth and non-ferrous metals necessary for the country's industry, the basing of the Northern Fleet as the most important component of the country's defense capability require good health of all categories of workers and military 
personnel of the continental zone and the Arctic islands in the Far North. Psychoneurological diseases, including those associated with disorders of visual perception, developing on the basis of the "polar tension syndrome», acquire special significance in these conditions. Based on the results of generalization of the views existing in the scientific literature on the integrity of the mechanisms of visual perception, a two-dimensional classification of various forms of its variability has been developed, which can be used as a methodological basis for the construction of virtual and physical medical landscapes in recreational areas of military facilities, departmental sanatoriums and rest homes for prophylaxis and treatment of neuropsychiatric disorders caused by functional disorders of the body due to the impact of "polar load» and prolonged stay in closed technological spaces.

Key words: marine medicine, landscape therapy, visual perception, closed spaces, psychoneurological disorders of visual perception

*Contact: Zhirov Vladimir Konstantinovich, v_zhirov_1952@mail.ru

Конфликт интересов: авторы заявили об отсутствии конфликта интересов.

Для цитирования: Жиров В.К., Закревский Ю.Н., Гонтарь О.Б., Мегорский В.В., Койгерова А.А., Маурчева П.А. Ландшафтная терапия нарушений зрительных восприятий на Крайнем Севере (обзор литературы) // Морская медицина. 2021. Т. 7, № 1. С. 7-19, http://dx.doi.org/10.22328/2413-5747-2021-7-1-7-19.

Conflict of interest: the authors declare no conflict of interest.

For citation: Zhirov V.K., Zakrevsky Yu.N., Gontar O.B., Megorsky V.V., Koigerova A.A., Maurcheva P.A. Landscsape therapy for disorders of visual perception in the Far North // Marine Medicine. 2021. Vol. 7, No. 1. P. 7-19, http://dx.doi.org/10.22328/2413-5747-2021-7-1-7-19.

В последние годы освоение арктических территорий является одним из основных приоритетов государственной политики России. Активное освоение арктического континентального шельфа с добычей больших объемов нефтепродуктов, продолжение фонкционирования известных горнорудных предприятий Кольского Севера по добыче необходимых для промышленности страны редкоземельных и цветных металлов, базирование и активная боевая подготовка Северного фрлота как важнейшей составляющей оборонного потенциала страны требуют хорошего состояния здоровья всех категорий работников континентальной зоны и арктических островов на Крайнем Севере, а также военнослужащих и обслуживающего военные объекты гражданского населения. Особое значение в этих условиях приобретают психоневрологические заболевания, в том числе связанные с нарушениями зрительного восприятия, развивающиеся на почве «синдрома полярного напряжения» Наблюдающийся в последние годы рост частоты патологий этого типа вынуждает искать более совершенные подходы к их профилактике и лечению, вследствие чего становятся все более популярными немедикаментозные методы, обеспечивающие снижение психологической нагрузки в технических помещениях, локальных зонах отдыха и санаторных комплексах и не оказывающие при этом побочного действия.

Одним из таких методов является садовая терапия (СТ), использующая психофизиологиче- ские эфрфекты общения человека с миром растений. В СТ выделяют активное и пассивное (ландшафтное) направления. Первое основано на фризических контактах с растениями и по существу представляет собой разновидность трудотерапии; во втором - положительное воздействие растений на психику и нервную систему осуществляется через зрительное восприятие отдельных фрлористических композиций и садово-парковых ландшафртов [1, с. 18-26]. С конца XIX - начала XX века в CША, а затем и в Европе СТ получила новое развитие и сейчас в ряде стран Старого и Нового Света официально существует в качестве самостоятельного психотерапевтического социализирующего направления [4, с. 177-179; 5, с. 11-12; 6, с. 272-273]. В Советском Союзе и России СТ почти не применялась, однако за последние годы ее популярность в нашей стране явно выросла: увеличилось число заинтересованных к ней лечебных учреждений и посвященных ей публикаций. Среди отечественных учреждений, работавших в этом направлении, следует назвать ботанические сады Иркутского и Тверского государственных университетов, а также Полярно-альпийский ботанический сад-институт, Никитский ботанический сад, Федеральный научный центр реабилитации инвалидов им Г.А. Альбрехта и немногие другие [7, с. 121-123; 8, с. 12-14]. Важным шагом в этом направлении является организация при Совете ботанических садов РФ комиссии по фритореабилитации в 2016 г. 
Несмотря на то, что психотропные возможности ландшафртов подтверждаются многовековым опытом мировой садово-парковой культуры, в большинстве современных реабилитационных программ пассивная СТ обычно только дополняет их активную составляющую. Создание теории лечебных ландшафтов значительно расширит возможности их применения во врачебной практике, все более регламентируемой в последние годы. Важным условием ее развития является синтез современных представлений психофизиологии зрительного восприятия и традиций конкретной культурообразующей среды.

Если положительные результаты активной СТ в общем несложно объяснить ее прямым воздействием на опорно-двигательный аппарат и сердечно-сосудистую систему человека, то интерпретация эфрфектов пассивно созерцаемого ландшафта требует синтеза различных, даже противоречивых, представлений о психофизиологических основах зрительного восприятия. Основным «камнем преткновения» здесь является проблема структурно-фрункциональной целостности воспринимающих систем. По отношению к ней существующие мнения можно разделить на утверждающие пространственную и временную разобщенность процессов проксимальной стимуляции и восприятия [9, с. 38-41], либо их интегрированность вплоть до континуального уровня [10, с. $112-114]$.

Первый подход основан на представлениях о зрительном восприятии как причинно-следственной цепи последовательных реакций, от возбуждения фоторецепторных клеток сетчатки глаза и преобразования электромагнитного излучения в нервные импульсы, до их передачи в кору головного мозга и формирования зрительного образа. Традиционное объяснение этих функций в терминах современной биофизики и нейрофизиологии оставляет нерешенным вопрос о взаимодействии соматических и психических структур, оставляя между ними понятийный пробел. Альтернативный, психософский, подход связан с утверждением принципа пространственно-временного психосоматического континуума [11, с. $160-161,198]$, который лежит в основе разных типов восприятия, включая зрительное.

Впервые семантический синтез чувственного рассудочного осуществил И. Кант, с помощью категории времени, трансцедентальная при- рода которого позволяет соединять понятия разной модальности [12, с. $87-88 ; 13$, с. 9-11].

Примерно 150 лет спустя аналогичный подход применил американский психолог Джеймс Джером Гибсон в своей теории «непосредственного», или «экологического», восприятия, доведя целостность зрительного восприятия до уровня «...увств как воспринимающих систем» $[10$, с. $11-12 ; 14$, с. 70$]$.

Однако трансцедентальную природу имеет не только время, но и пространство, и за три десятка лет до появления первых работ Дж. Гибсона православный священник, известный богослов и математик о. Павел Флоренский использовал эту категорию для обоснования духовного значения обратной перспективы при формировании перцептивного образа $[15$, с. 4 ; 16 , с. $6 ; 17$, с. 13]. По его мнению, привычный для нас образ открытого пространства линейной перспективы является только иллюзией, которая создается в результате взаимодействия: 1) изменений размера зрачка, формы глазного яблока и хрусталика глаза; 2) бинокулярности зрения; 3) подвижности глаз, головы, и всего тела (т.е. локомоций) наблюдателя; 4) подвижности самого объекта наблюдения, наконец, 5) психических механизмов фрормирования перцептивного образа [15, с. 72]. В частности, дети до определенного возраста воспринимают пространство в обратной перспективе, и только с утерей непосредственного отношения к миру дети утрачивают обратную перспективу. Впоследствии данный факт неоднократно подтверждался и другими авторами $[15$, с. 72 , с. $85 ; 18$, c. 4-5, 15]. Обратная и/или аксонометрическая перспектива может доминировать в зрительном восприятии некоторых взрослых людей, постоянно пребывающих в пространствах открытых монотонных ландшафртов [18, с. 10, 14]. На близком расстоянии от визуально воспринимаемого объекта в перцептивном пространстве наблюдателя могут чередоваться различные (прямая, аксонометрическая или обратная) перспективы, периодически сменяя друг друга при константном положении точек перехода между ними [19, с. 277]. По-видимому, представители некоторых этнических групп способны сочетать незавуалированное локомоциями «туннельное» восприятие близкорасположенных предметов в линейной перспективе с обратно-перспективным восприятием более удаленных предметов [21, с. 31]. 
Ключевая роль подвижности позволяет обобщить все данные представления в виде бинарной оппозиции: «подвижность - покой» (1). Подвижность воспринимающих систем и локомоции наблюдателя могут реализоваться при сохранении их пространственной целостности, либо в результате снижения ее уровня, т.е. распада на составляющие элементы. Вследствие этого базовую оппозицию (1) можно представить в форме истинной триады (2) (рис. 1).

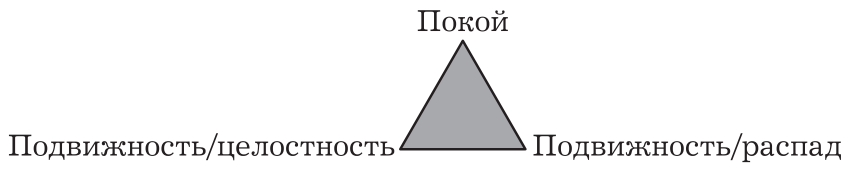

Рис. 1. Подвижность воспринимающих систем и локомоции наблюдателя как механизм «подвижность/целостность - покой подвижность/распад»

Fig. 1. The mobility of the perceiving systems and the locomotion of the observer as a mechanism of «mobility/integrity-rest-mobility/decay»

Принимая во внимание, что в идеальном случае преобразование подвижной целостной системы в совокупность независимых друг от друга подвижных элементов с необходимостью включает в себя мгновенное состояние «нулевой» подвижности, при котором система прекращает свое существование как единое целое, логично преобразовать истинную триаду (2) в триаду вырожденную. В отличие истинной триады, вершина которой расположена на качественно отличном от составляющих исходную бинарную оппозицию семантическом уровне, вершина вырожденной триады находится на одном с ними уровне, графически - на одной прямой. Восприятие пространства в обратной перспективе не зависит от активности локомоций, так как, оно является рудиментом древнего и более совершенного зрения, утраченного человеком в процессе эволюции. В переходной - аксонометрической перспективе, или «нулевой» точке - пространственное восприятие не создает объемного образа, поскольку в ней размеры воспринимаемого объекта не изменяются с расстоянием. Изменение геометрии перцептивного пространства при переходе к прямой перспективе связано с уменьшением числа его измерений вплоть до одного, если этот переход не маскируется факторами подвижности, повышающими целостность пространственного восприятия. Последующая деградация теоретически должна привести к тому же конечному результату, что и в случае расщепления зрительного восприятия, т.е. к его прекращению [20, с. 4] (рис. 2).

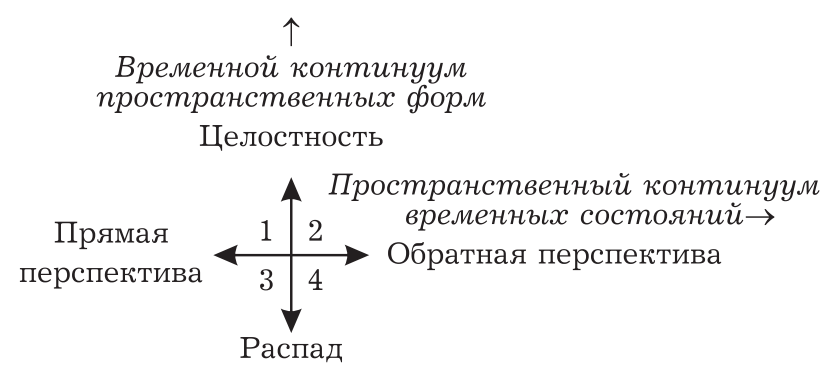

Рис. 2. Оси координат, представленные оппозициями: целостность - распад, прямая перспектива - обратная перспектива

Fig. 2. Coordinate axes represented by oppositions: integrity - decay, forward perspective - reverse perspective

Вместе с нулевой точкой аксонометрии/неподвижности поле возможных состояний перцептивного пространства делится на четыре сектора, каждый из которых ограничен векторами двух типов: изменений подвижности ООС и вариаций перспективы пространственного образа. В направлениях, обозначенных векторами обратной перспективы или целостности, в процессе зрительного восприятия должно происходить образование пространственного континуума временных состояний или временного континуума пространственных форм, соответственно [23, с. 11-12].

В патофизиологическом процессе зрительного восприятия человека психофизиологические основы некоторых известных нарушений зрительного восприятия и связанных с ними синдромов могут обсуждаться с позиций предложенной двумерной классификации разнообразия пространственно-временных состояний его систем - клаустрофобия и агорафобия [24, с. 51-52]. Среди наиболее известных психоневрологических патологий, связанных со зрительным восприятием пространства, эти синдромы привлекают наибольшее внимание. Во многих случаях признаки клаустрофобии проявляются с осознанием отсутствия свободы передвижения и поведения в целом, т.е. туннелированности фризического и социального пространств, особенно выраженной в условиях современного города [25, с. 128$]$.

Альтернативный синдром агорафобии, проявляющийся в форме боязни открытых пространств и больших скоплений людей, возни- 
кает как следствие избыточной активности психофизического механизма, усиливающего иллюзию открытости вплоть до утраты осторожности, что, раньше или позднее приводит к травматическим последствиям, наиболее частым у детей младшего возраста, или лиц, пребывающих в состоянии алкогольного или наркотического опьянения. В результате психической переработки травматического опыта в таких случаях может сорормироваться устойчивая ассоциация открытого пространства с чувством опасности. Таким образом, синдромы клаустро- и агорафробии можно представить как издержки пространственной перцепции в секторе 1 (см. рис. 2), в котором линейная перспектива сочетается с высокой целостностью зрительного восприятия и подвижностью элементов его механизма. Недостаточная или чрезмерная завуалированность перцептивного «туннеля» приводит, соответственно, к его реалистичному - одномерному - восприятию вместе с драматическим осознанием недоступности выхода либо к неожиданному появлению травмирующих препятствий. Восприятие пространства в обратной перспективе предотвращает развитие указанных фобий: демонстрацией более высоких уровней организации пространства в первом случае либо устранением этой декорации - во втором [25, с. 129].

Нарушения константности восприятия (HКВ) достаточно редкий синдром, объединяющий симптомы разнообразных нарушений зрительного восприятия - размеров, пропорций, ракурсов, а также спонтанных перемещений объектов окружающего пространства. Важно, что последние возникают только во время движения пациента, а при его остановке исчезают. В подавляющем большинстве случаев страдающие НКВ пациенты способны распознавать предметы и сохраняют критичность относительно своего состояния [25, с. 130]. Поскольку симптомы НКВ связаны с движением, логично предположить, что особенности зрительного восприятия, обусловливающие этот синдром, связаны с секторами 1 и 4 на рис. 2. Расщепление перцептивного образа, или апперцептивная агнозия Лиссауэра - распространенный симптом, при котором отдельные элементы на- блюдаемого объекта не интегрируются в единый образ и в целом структура объекта не воспринимается. При нем, как и при других агнозиях, пациенты обычно не узнают и не могут вспомнить ранее виденное. В психопатологическом смысле апперцептивная агнозия является альтернативой НКВ, занимая секторы 2 и 3 , поскольку, в отличие от нее, связана с расщеплением зрительного образа. Усиление прямой перспективы при достаточно выраженном расщеплении образа в секторе 2 (см. рис. 2) может привести к симптому симультанной агнозии, при котором пациент способен к зрительному восприятию только одного из нескольких находящихся рядом объектов. С этой точки зрения к нему близок симптом Балинта, при котором эффректы симультанной агнозии усиливаются благодаря глазодвигательной апраксии [26, с. $65-66 ; 27$, с. $153-155 ; 28$, с. 9-10].

В целом девиации зрительного восприятия, связанные с расщеплением перцептивного образа, связаны с возрастной изменчивостью, наиболее сильно проявляясь у детей младшего школьного возраста, а в период от 8 до 13 лет восприятие развивается в направлении его интегрированности. По-видимому, дальнейшее сокращение поля зрения в результате развития этого симптома вместе с усилением прямой перспективы может привести к уменьшению размерностей перцептивного пространства вплоть до одного измерения или полного прекращения зрительного восприятия ${ }^{1}$.

Многочисленные сведения в литературе о возможном психологическом воздействии садов и парков указывают на возможность коррекции нарушений зрительного восприятия путем созерцания ландшафтов определенной пространственной организации. Геометрическое разнообразие перцептивного пространства определяется изменчивостью его перспективы, локомоциями и подвижностью наблюдаемого объекта. Психотропная активность ландшафта обусловлена определенным сочетанием этих факторов, специфичных относительно конкретных видов нарушений восприятия и психофизических особенностей самого наблюдателя. Однако далеко не всегда можно разграничить нормальное и патологическое фрормирование зрительного образа, как и вообще

\footnotetext{
${ }^{1}$ Гончаров О.А. Нейропсихологический анализ нарушений зрительного восприятия у детей с локальными поражениями мозга: Рукопись кандидатской диссертации. СПб., 1998. 184 с. [Goncharov O.A. Neuropsychological analysis of visual impairments in children with local brain lesions / Manuscript of Ph.D. thesis. Saint Petersburg, 1998, 184 p. (In Russ.)].
} 
психическую норму и нарушения психики. В контексте установившихся на данную проблему взглядов однозначно различаются только континуальные и дискретные типы зрительного восприятия. Но поскольку между ними существует целый спектр переходных форм, многообразие которых далеко не всегда можно выразить терминами современной психофизиологии, а интерпретация во многом зависит от научной позиции автора, для их определения требуется более емкий понятийный аппарат. Его основные принципы обсуждались выше и были положены в основу предлагаемой классификации различных форм зрительного восприятия, согласно схеме.

Так как геометрические характеристики традиционных садов, в том числе определяющие их психотропные свойства, являются производными соответствующей культурной среды, их невозможно формализовать, не прибегая к духовным основам базовой культуры. Для китайского садового искусства, сформировавшегося более трех тысяч лет назад на основе синтеза религиозно-философрских систем даосизма, конфуцианства и буддизма, это имеет особое значение [30, с. 11-14]. Китайская культура является лидером по технологиям моделирования перцептивного пространства и формирования определенных зрительных образов через психофизическое воздействие искусственных ландшафртов.

Проблема лечебных садов имеет продолжительную историю, однако в подавляющем большинстве случаев в различных (особенно древних языческих) культурах их терапевтическая функция лишь дополняла основную религиозную. С этой точки зрения особый интерес представляют китайские сады, гармонически сочетающие духовное с материальным, в частности, терапевтическим. Именно поэтому с древних времен в Китае сад использовался как в эстетических, так и лечебных целях [31, с. 13-16]. Высокий уровень технологий психологического воздействия, достигнутый в садово-парковой культуре древнего и средневекового Китая, позволяет использовать этот опыт при создании теоретических основ современной ландшафтной терапии. Ведущий отечественный специалист по дальневосточным садам Е. В. Голосова высказывала в связи с этим сомнение «..о правомерности и рациональности использования учения, в основу которого заложена определенная география местности и присущие ей экологические параметры и законы, для других географических зон» [30, с. 17].

Более тысячелетия назад в китайской области Сучжоу, расположенной в нижнем течении реки Янцзы и отличающейся разнообразием форм классических садов, была разработана классификация, включающая следующие типы садовых ландшафтов: 1) противоположных образующих различные картины, последовательно раскрывающиеся для зрителя в проемах архитектурных конструкций при его движении; 2) открытых - обеспечивающих восприятие нескольких картин одновременно; 3) разделенных - последовательно раскрывающих для зрителя отдельные участки сада по принципу анфилады дворцовых комнат при его движении; 4) сквозных - построенных по принципу почти полностью разделенных перегородками участков, через небольшие проемы в которых просматриваются конструкции соседних кластеров, и 5) заимствованных - использующих фрагменты внешних пейзажей, вписанных в общую ландшафтную конструкцию сада [30, с. 27-29].

Суммируя сказанное, древнекитайскую классификацию ландшафтов можно спроецировать на схему следующим образом (рис. 3).

Можно отметить, что представленная на рис. 2 классификация возможных состояний зрительного восприятия в целом согласуется с сучжоусской классификацией китайских садовых ландшафтов. При этом оппозиция противоположного - сквозного пейзажей соответствует связанной с локомоциями оппозиции целостности - распада пространственного восприятия, а оппозиция заимствованного - открытого пейзажей - пространства, иллюзорно воспринимаемого в обратной или прямой перспективе.

Сходный характер этих классификаций позволяет рассматривать их совокупность [30, с. 32-41], как методологическую основу алгоритма создания лечебных садов и парков. В качестве общего принципа целесообразно использование традиционного для китайской ландшафтной архитектуры и живописи приема активного управления восприятием создаваемого или изображаемого пространства.

В связи с этим особое значение приобретают: 1) разделение территории сада на отдельные участки, соединенные друг с другом переходами; 2) диффреренциация пространства сада не только по горизонтали, но и по вертикали с по- 


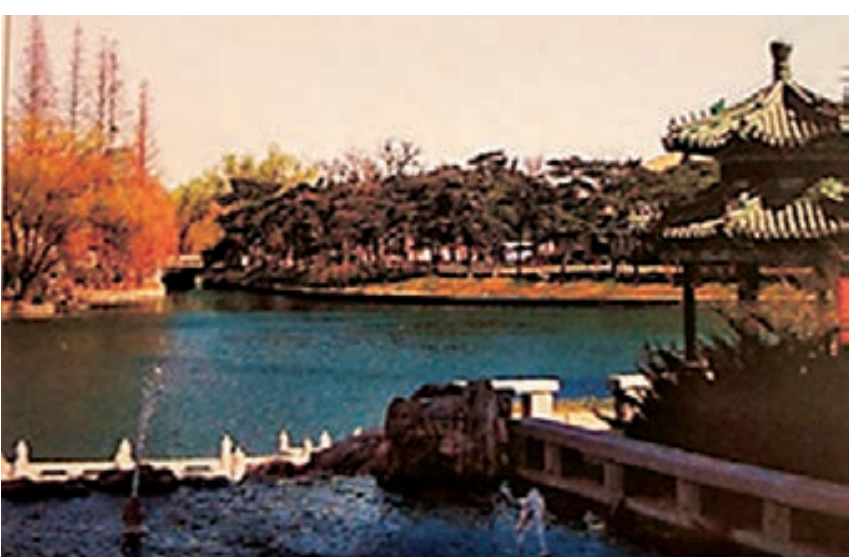

Открытый пейзаж, правительственная резиденция Дяоюйтай, Пекин

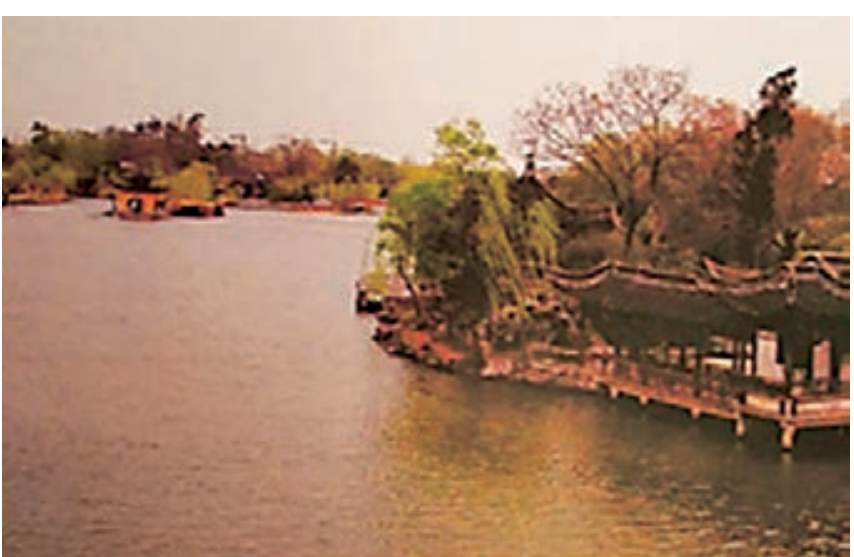

Противоположный пейзаж, Шоусиху, Янчжоу

Рис. 3. Типы садовых ландшафртов (открытый и противоположный) по Сучжоу

Fig. 3. Types of garden landscapes (open and opposite) by Suzhou

мощью возвышенностей, камней и водоемов; 3) манипулирование разнообразными оптическими эфрфектами, благодаря которым изменяются не только тип перспективы, но и размеры отдельных элементов, так же как и его облик в целом. Поскольку существует значительное разнообразие геометрических особенностей перцептивного пространства не только у пациентов с различными нарушениями психики, но и у психически здоровых лиц, для дальнейшего развития этого направления принципиальным является изучение изменений целостности пространственного восприятия при различных психоневрологических заболеваниях, и зависимости психофизических эфрфектов визуального восприятия ландшафта от характера его пространственной организации [18, с. 4-5; 19, с. 277; 20, с. 4].

У контингентов работающих и несущих службу в замкнутых пространствах, в том числе конвергированных условиями Крайнего Севера, необходим комплекс мер, направленных на коррекцию психоэмоциональных депрессивных и психофизиологических состояний длительного воздействия сенсорного голода и визуальных оптических ограничений. Сложность технической организации и конструкции подводных лодок, отличающихся ограниченностью и замкнутость внутреннего пространства при высокой концентрации технических устройств, в условиях инфрормационной и социальной изоляции и постоянной опасности для жизни, психологически значительно усложняют адаптацию личного состава к выполнению профрессиональных обязанностей [32, с. 16-18].
В значительной степени эта проблема решается с помощью комплекса совместных психологических тренингов экипажей в предпоходовый период, обеспечивающих взаимную поддержку и совместное преодоление трудностей в экстремальных условиях замкнутого пространства. По результатам психологических обследований, преобладание «высокого и выше среднего» уровней групповой сплоченности выявлено у большинства $(87 \%)$ членов экипажей подводных лодок, а уровни «ниже среднего» и «низкий» в данной выборочной совокупности диагностированы не были [32, с. 19-20]. Несмотря на это, для укрепления непосредственных военно-профессиональных и межличностных контактов между членами похода малые социальные группы моряков в условиях длительного автономного пребывания под водой, целесообразно использовать методы визуального расширения психосенсорного оптического пространства [33, с. 42-44; 34, с. 128-133] (рис. 4).

Высокие показатели психологического климата в экипаже моряков-подводников, стабильные психофизиологические и иммунобиологические показатели высокие индивидуальные психологические показатели - уровень самооценки, мотивация достижений, нервнопсихическая устойчивость (НПУ), коммуникативный потенциал,- в условиях Кольского Заполярья достигаются нивелированием депрессивных и психофизиологических состояний длительного воздействия сенсорного голода всеми методами психологических и психофизиологических тренировок [35, с. 83-87 $]^{1}$.

\footnotetext{
${ }^{1}$ https://www.ncbi.nlm.nih.gov/books/NBK45747/pdf/Bookshelf_NBK45747.pdf.
} 


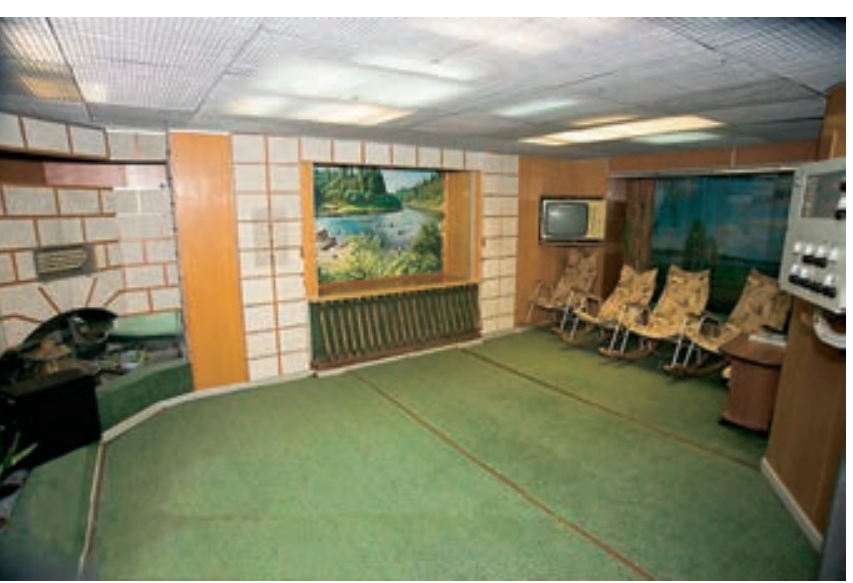

Рис. 4. Каюта психологической разгрузки экипажа атомной подводной лодки с встроенным экраном для смены ландшафртного изображения (из открытых источников информации)

Fig. 4. The cabin for psychological unloading of the crew of a nuclear submarine with a built-in screen

for changing the landscape image (from open sources of information)

Отчасти сходным, но имеющим свои специфрические особенности является комплекс фракторов, действующий на контингенты, проходящие военную службу на островах Арктической зоны Российской Федерации. По сравнению с условиями службы подводников во время продолжительных походов, к психологическому воздействию закрытых пространств в этих случаях могут добавиться до сих пор малоизученные эффекты их контраста с восприятием открытых тундровых пространств арктических островов [36, с. 7-8; 37, с. 91-92].

При организации медицинского обеспечения контингентов Министерства обороны должны учитываться все особенности зрительных стимулов, испытываемых в замкнутых пространствах субмарин, и контрастных сочетаний, оказывающих сходное воздействие помещений административно-жилых комплексов с эффектами монотонных ландшафтов арктических пустынь военнослужащими, находящимися в специфических условиях отдаленных островных гарнизонов. В последнем случае, кроме чисто визуальных эфффектов, они подвергаются воздействию суровых климатических условий и геофизических фракторов с низкими температурными показателями воздуха, приводящих к повышенным психофризиологическим нагрузкам и декомпенсации резервных возможностей организма, приводящим к развитию сердечно-сосудистых, дегенеративно-дистро- фических, пульмонологических и др. заболеваний $[38$, с. $140-141 ; 39$, с. 175-178]. Для психофизиологической разгрузки зрительного анализатора в замкнутом пространстве в т.ч. при выявлении индивидуално-психологических предикторов дезадаптации у контингента в островной арктической зоне в построенных современных административно-жилых комплексах созданы помещения с потолочным остеклением для эффекта расширения пространства и комнаты отдыха с элементами сменяемого ландшафтного дизайна на экранах встроенных мониторов [40, с. $36-42 ; 41$, с. 4-6] (рис. 4, 5).

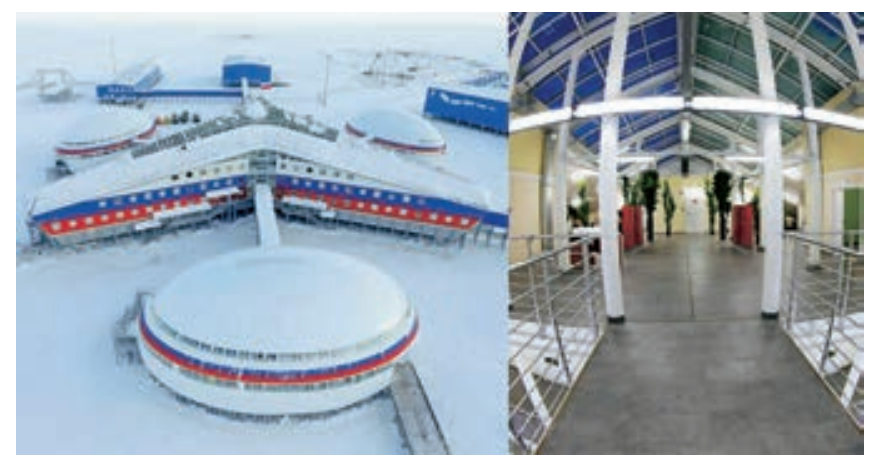

Рис. 5. Административно-жилой комплекс на о. Земля Александры с потолочным остеклением помещений и элементами ландшафтного дизайна

Fig. 5. Administrative and residential complex on the island of Alexandra Land with ceiling glazing of premises and elements of landscape design

Современные технологии компьютерной графикки создают широкие возможности в этом направлении, позволяя моделировать виртуальные модели ландшафтов, организация пространства которых будет адаптирована к индивидуальным особенностям зрительного восприятия в соответствии с предложенной двумерной классификацией (рис. 2). Для медицинского наблюдения, профилактики и лечения острых заболеваний у военнослужащих сформированы амбулатории с современной медицинской аппаратурой, операционными, реанимационными, клиническими лабораториями, рентгеновской и УЗИ аппаратурой и аппаратной телемедицинских консультаций [39, с. 21-23]. Предупреждение дезадаптивных расстройств, астенических состояний, авитаминозов, кожных и гнойничковых заболеваний достигается мероприятиями фозических тренингов в тренажерных залах, витаминизацией и ультрафиолетовой инсоляцией, правильным сбалансированным питанием при составлении меню- 
раскладок, своевременной реабилитации после травм и заболеваний, психологических разгрузок в комнатах отдыха с элементами смены ландшафтного дизайна [42, с. $1397-1406 ; 43$, с. 10-13] $]^{1}$.

Резистентность как мера эфроективности адаптации сенсорной (зрительной, тактильной, слуховой), сердечно-сосудистой, респираторной, костно-мышечной систем в Арктике зависит от функционального резерва биосистемы. В оризиологии фрункциональный резерв определяется как готовность организма, отдельной системы или органа выполнять заданную фрункцию в заданное время с минимальным напряжением регуляторных механизмов, т.е. наиболее экономным способом. Качественно особое состояние необходимости адаптироваться к условиям Крайнего Севера, отличающееся от нормы и патологии определено как «синдром полярного напряжения». В рамках этого синдрома у отдельных представителей новой северной популяции может развиваться стойкое утомление функциональных систем со снижением эфорективности системообразующих факторов и последующей дезинтеграцией межорганных и межсистемных связей в том числе зрительной фрункции [44, с. 104-108].

В работах академика В. П. Казначеева выделены два конституциональных типа, обладающих различными феногенетическими характеристиками адаптации к полярным условиям жизни. Первый конституциональный тип, обозначенный как «спринтер», способен осуществлять мощные фризиологические реакции с высокой степенью надежности в ответ на значительные, но кратковременные колебания фракторов внешней среды. Однако высокий уровень надежности физиологических реакций может поддерживаться лишь относительно короткий срок. Второй конституциональный тип, «стайер», может выдерживать довольно продолжительные равномерные воздействия фракторов внешней среды в неадекватных условиях. Наряду с этими крайними конституциональными типами существуют промежуточные, получившие общее название «микстов». Организмы этих людей отличаются количественным соотношением форменных элементов крови, ее свертываемостью, рядом фрункциональных показателей кардиореспираторной системы, биохимическими, психоэмоциональными и морфологическими показателями, па- раметрами фонкционирования поперечнополосатой мускулатуры [45, с. 36-37].

В работе Ю.Г. Солонин и Е.Р. Бойко (2017) показано, что для Крайнего Севера характерны резкие сезонные колебания ряда фракторов с наибольшим количеством заболеваний на середину полярной ночи: острые синуситы, острые заболевания верхних дыхательных путей, внегоспитальные пневмонии среднетяжелого и тяжелого течения и др. Во многом это может быть причиной зимней депрессии - сходного с психическим заболеванием «сезонного афрфективного расстройства». Установлено уменьшение нервно-мышечной иннервации, связанной со снижением проводящих свойств сенсорных и моторных волокон [46, с. 36-38; 47, с. 100-102]. Сужение сосудов и повышение гематокрита вследствие переохлаждения лобной области повышает уровень гематокрита, вязкость и реологическое сопротивление крови, что влияет на функционирование зрительного нерва и вспомогательного аппарата глаза [48, с. $674-680 ; 49$, с.1428-1431, 50, с. 559-561].

Заключение. Двумерная классификация различных форм изменчивости зрительного восприятия может использоваться в качестве методологической основы конструирования виртуальных и фризических лечебных ландшафтов в рекреационных зонах отдыха военных объектов, ведомственных санаториях и домах отдыха в целях профилактики и лечения фрункциональных нарушений организма вследствие длительного пребывания в замкнутых технологических пространствах. У новых популяций людей, проживающих и работающих на Крайнем Севере, стойкое утомление функциональных систем при «синдроме полярного напряжения» со снижением эфрективности системообразующих фракторов и последующей дезинтеграцией межорганных и межсистемных связей и зрительной функции требует их восстановления, в том числе с использованием методов ландшафтной терапии.

Организация комплексов лечебных реальных и технических или электронных визуальных ландшафтов основана на двумерной целостности зрительного восприятия как результате взаимодействия локомоций и статических геометрических параметров окружающего пространства с приемом активного управления восприятием создаваемого или изображаемого

${ }^{1}$ https://fas.org/sgp/crs/misc/R41153.pdf. 
пространства: 1) разделение территории сада (изображаемого объекта) на отдельные участки (части); 2) дифреренциация пространства сада (объекта) не только по горизонтали, но и по вертикали; 3) манипулирование разнообразными оптическими эффектами, благодаря которым изменяются не только тип перспективы, но и размеры отдельных элементов.
Восстановление и приближение к норме нарушений зрительных фрункций у людей в Арктической зоне должны проводиться в комплексе всех методов и методик повышения эффективности адаптации сенсорной (тактильной, слуховой), сердечно-сосудистой, респираторной, костно-мышечной систем и всего функционального резерва организма.

\section{ЛИTЕРАTУРA/REFERENCES}

1. Хаснулин В.И. Введение в полярную медищину. Новосибирск: СО РАMH, 1998. 337 с. [Hasnulin V.I. Introduction to polar medicine. Novosibirsk: SO RAMS, 1998, 337 p. (In Russ.)].

2. Голиков К.А. Садово-парковые комплексы мира: регионоведение, политика, межкультурная коммуникация. М.: МГУ, 2017. 208 c. [Golikov K.A. Garden and park complexes of the world: regional studies, politics, intercultural communication. Moscow: MSU, 2017, 208 p. (In Russ.)].

3. Лихачев Д.С. Писъма о добром и прекрасном. М.: Детская литература, 1988. 218 с. [Lichachev D.S. Letters about the good and the beautiful. Moscow: Publishing house Children's literature, 1988, 218 p. (In Russ.)].

4. Matsuo E. What is «Horticulture Wellbeing» In Relation to "Horticulture Therapy»? Towards a New Millennium in People-Plant Relationships / eds. M.D.Burchett, J.Tarran, R.Wood. University of Technology. Sydney: Sydney Printing Services, 1998. P. 174-180.

5. Ranjan D. Community garden: A bridging program between formal and informal learning // Cogent Education. 2016. Dec. No. 3. 1177154.14 p.

6. Wichrowski M., Whiteson J., Haas F., Mola A., Rey M. Effects of horticultural therapy on mood and heart rate in patients participating in an inpatient cardiopulmonary rehabilitation program // J. Cardiopulmonary Rehabilitation. 2005. Vol. 25, No. 5. P. 270-274.

7. Гонтарь О.Б., Жиров В.К., Шестаков А.В. Научные основы специализированного ландшафтного дизайна // Научные основы экологии, мелиорации и эстетики ландиафтов: материалы конференции. Тула: Гриф и К, 2010. С. $120-125$. [Gontar O.B., Zhirov V.K., Shestakov A.V. Scientific foundations of specialized landscape design. Scientific foundations of ecology, melioration and landscape aesthetics: Conference proceedings. Tula: Publishing house Grif \& K, 2010, pp. 120125 (In Russ.)].

8. Сизых С.В., Кузеванов В.Я., Белозерская С.И., Песков В.П. Садовая терапия: Использование ресурсов ботанического сада для адаптации и реабилитации. Справочно-методические пособие. Иркутск: Изд-во Ирк. гос. ун-та, 2006. 48 c. [Sizych S.V., Kuzevanov V.Ya., Belozerskaya S.I., Peskov V.P. Horticultural therapy: Using the resources of the botanical garden for adaptation and rehabilitation. Reference and methodological manual. Irkutsk: Publishing house of the ISU, 2006, 48 p. (In Russ.)].

9. Вундт В. Очерк психологии. СПб.: Изд-во Ф. Павленкова, 1896. 229 с. [Vundt V. Psychology outline. Saint Petersburg: Publishing house of the F. Pavlenkov, 1896, 229 p. (In Russ.)].

10. Гибсон Дж. Экологический подход к зрительному восприятию. М.: Прогресс, 1988. 464 c. [Gibson J. An ecological approach to visual perception. Moscow: Publishing house Progress, 1988. 464 p. (In Russ.)].

11. Курпатов А.В., Алехин А.Н. Филособия психологии. Новая методология. М.: ЗАО «ОЛМА Медиа Групп», 2006. 448 c. [Kurpatov A.V., Alekhin A.N. Philosophy of psychology. New methodology. Moscow: Publishing house CJSC OLMA Media Group, 2006, 448 p. (In Russ.)].

12. Кант И. Критика чистого разума. 1964 // Сочинения в 6 mомах / под общ. ред. В.Ф. Асмуса, А.В. Гулыги, Т.И. Ойзермана. М.: Мысль, 1963. Т. 3. 799 с. (Серия «Философское наследие»). [Kant I. Critique of Pure Reason. 1964. Works in 6 vol. ed. by V.F. Asmus, A.V. Gulyga, T.I. Oizerman. 1963. Moscow: Publishing house Thought, Vol. 3 , 799 p. (Series Philosophical Heritage) (In Russ.)].

13. Гайденко П.П. Проблема времени у Канта: время как априорная форма чувственности и вневременность вещей в себе // Вопросы фбилособии. 2003. № 9. С. 134-150. [Gaidenko P.P. The problem of time in Kant: time as an apriori form of sensibility and timelessness of things in themselves. Questions of philosophy, 2003, No. 9, pp. $134-150$ (In Russ.)].

14. Covarrubiasa P., Jimeneza A.A., Cabreraa F., Costal A. The Senses Considered as Perceptual Systems: The Revolutionary Ideas of Gibson's 1966 Book, 50 Years Later - Part 1 // Ecological Psychology. 2017. Vol. 29, No. 2. P. 69-71. 
15. Флоренский П.А., священник. Обратная перспектива // Сочинения в 4 толах. Т. 3 (1). М.: Мысль, 1999. С. $46-98$. [Florensky P.A., priest. Reverse perspective. Works in 4 vol. Vol 3 (1). Moscow: Publishing house Thought, 1999, pp. 4698 (In Russ.)].

16. Перетятькин Г.Ф. Мир в прямой и обратной перспективе: размышления на тему Флоренского // Научнъе ведомости БелГУ. Филособбия. Социология. Право. 2009. № 10 (65). Вып. 9. С. 5-18. [Peretyatkin G.F. The World in Direct and Reverse Perspectives: Reflections on the Theme of Florensky. Scientific Bulletin of BelSU. Philosophy. Sociology. Law, 2009, No. 10 (65), Iss. 9, pp. 5-18 (In Russ.)].

17. Kaplan G.A. Kinetic disruption of optical texture: The perception of depth at an edge // Perception and Psychophysics. 1969. Vol. 6. P. 193-198.

18. Гончаров О.А. Закономерности восприятия и изображения перспективных отношений // Психологический журнал Международного университета природъ, общества и человека "Дубна». 2009. № 4. C. 1-15. [Goncharov O.A. Regularities of perception and image of perspective relationships. Psychological journal of the International University of Nature, Society and Man «Dubna», 2009, No. 4, pp. 1-15 (In Russ.)].

19. Койгерова А.А. Особенности пространственного восприятия лиц с психическими расстройствами как основа построения лечебных ландшафтов // Вестник уральской медицинской академической науки. 2019. Т. 16 , № 2. C. 273-278. [Koygerova A.A. Peculiarities of spatial perception of persons with mental disorders as the basis for constructing therapeutic landscapes. Bulletin of the Ural Medical Academic Science, 2019. Vol. 16, No. 2, pp. 273-278 (In Russ.)]. doi: 10.22138/2500-0918-2019-16-2-273-278.

20. Жиров В.К., Гонтарь О.Б., Койгерова А.А. Особенности геометрии перцептивного пространства при психических нарушениях (к вопросу о конструировании лечебных ландшафтов) // Topical areas of fundamental and applied research IV: Мат-лы IV Межд. научно-практ. конф., 4-5 августа 2014 г. North Charleston, USA. North Charleston: Create Space, 2014. Vol. 2. P. 4. [Zhirov V.K., Gontar O.B., Koigerova A.A. Peculiarities of the geometry of the perceptual space in mental disorders (on the question of designing therapeutic landscapes). Topical areas of fundamental and applied research IV: Materials of the IV International Scientific and Practical Conference, 4-5 August 2014, North Charleston, USA. North Charleston: Create Space, 2014, Vol. 2, pp. 4 (In Russ.)].

21. Жиров В.К., Гонтарь О.Б., Маурчева П.А. Особенности пространственной организации ландшафтов Кольского Севера в контексте духовности поморской и саамской культур // Север России - один из источников ее развития и единения народов: уроки истории: Сборник докладов региональной научно-практической конференции в рамках общественного форума «Всемирный Русский Народный Собор» 26-27 ноября 2015 года, г. Кировск Мурманской области / под ред. А.М.Ершова. Мурманск: Изд-во МГТУ, 2015. С. 27-32. [Zhirov V.K., Gontar O.B., Maurcheva P.A. Peculiarities of the spatial organization of the landscapes of the Kola North in the context of the spirituality of the Pomor and Sami cultures. North of Russia - one of the sources of its development and unity of peoples: the lessons of history. Collection of reports of the regional scientific and practical conference in the framework of the public forum «World Russian People's Council» November 26-27, 2015. Kirovsk, Murmansk region, ed. A.M.Ershov. Murmansk: Publishing house MSTU, 2015, pp. 27-32 (In Russ.)].

22. Баранцев Р.Г. Системная триада - структурная ячейка синтеза // Системные исследования. Методологические проблемы. Ежегодник 1988 / под ред. Б.М.Гвишиани и др. М.: Наука, 1989. С. 193-198. [Barantsev R.G. The system triad is a structural cell of synthesis. System research. Methodological problems. Yearbook 1988. ed. B.M.Gvishiani et al. Moscow: Publishing house Science, 1989, pp. 193-198 (In Russ.)].

23. Бергсон А. Творческая әволючия. СПб., 1914. 230 с. [Bergson A. Creative evolution. Saint Petersburg, 1914.230 p. (In Russ.)].

24. Жиров В.К., Гонтарь О.Б., Маурчева П.А. Лечебные ландшафты в контексте психологии пространственного восприятия: традиции и современные подходы // Ландшабтная архитектура в ботанических садах и дендропарках: материалы IX Международной научно конференции / отв. ред. д.с.-х.н. Е.В.Голосова, науч. ред. к.б.н. Н.А.Трусов; 4-6 сентября 2017 г. Соловки, 2017. С. 49-54. [Zhirov V.K., Gontar O.B., Maurcheva P.A. Healing landscapes in the context of the psychology of spatial perception: traditions and modern approaches. Landscape architecture in botanical gardens and arboretums: materials of the IX International scientific conference / executive ed. Doctor of Agricultural Sciences E.V.Golosova, researcher ed. Ph.D. N.A.Trusov; September 4-6, 2017. Solovki, 2017, pp. 49-54 (In Russ.)].

25. Волокитина Т.В., Зотова А.А., Попова Е.В., Синицкая Е.Ю. Коррекция нарушений зрителъного восприятия у слабовидящих детей. Архангельск: САФУ, 2013. 175 с. [Volokitina T.V., Zotova A.A., Popova E.V., Sinitskaya E.Yu. Correction of visual impairment in visually impaired children. Arkhangelsk: NArFU, 2013, 175 p. (In Russ.)].

26. Кудашкина Е.Ю., Сухих Е.А. Зрительная агнозия. Нейрофизиологические основы. Виды и методы выявления // Вестник совета молодых ученых и специалистов Челябинской области. 2017. Т. 3, № 4 (19). С. 64-67. 
[Kudashkina E.Yu., Sukhikh E.A. Visual agnosia. Neurophysiological foundations. Types and methods of detection. Bulletin of the Council of Young Scientists and Specialists of the Chelyabinsk Region, 2017, Vol. 3, No. 4 (19), pp. $64-67$ (In Russ.)].

27. Хомская Е.Д. Нейропсихология. 4-е изд. СПб.: Питер, 2005. 496 с. [Chomskaya E.D. Neuropsychology: $4^{\text {th }}$ ed. Saint Petersburg: Publishing house Piter, 2005, 496 p. (In Russ.)].

28. Фролова Ю.Г. Клиническая нейропсихология. Минск: БГУ, 2016. 111 с. [Frolova Yu.G. Clinical neuropsychology. Minsk: BSU, 2016, 111 p. (In Russ.)].

29. Parkinson A. Climate change and infectious disease: impact on human populations in the Arctic. Forum on Global Health. Washington: National Academy of Sciences, 2008. 162 p.

30. Голосова Е.В. Ландиабфтное искусство Китая. М.: Наталис, 2008. 327 с. [Golosova E. V. Landscape art of China. Moscow: Publishing house Natalis, 2008, 327 p. (In Russ.)].

31. Рандхава М. Сады через века. М.: Знание, 1981. 320 с. [Randhava M. Gardens through the centures. Moscow: Publishing house Knowledge, 1981, 320 p. (In Russ.)].

32. Королева И.Н., Караяни А.Г., Закревский Ю.Н. Влияние психологической групповой сплоченности у моряков-подводников на выполнение задач повседневной учебно-боевой деятельности // Армия и общество. 2015. № 4. С. 16-20. [Korolyova I.N., Karayani A.G., Zakrevsky Yu.N. Influence of psychological group cohesion in submariners on the performance of tasks of daily combat training activities. The army and society, 2015, No. 4, pp. 16-20 (In Russ.)].

33. Закревский Ю.Н. Королева И.Н., Караяни А.Г., Архангельский Д.А. Повышение адаптивного потенциала у молодых моряков-подводников в условиях Крайнего Севера // Морской медицинский журнал им Д.П.Зуихина. 2016. № 1. C. 40-46. [Zakrevsky Yu.N. Koroleva I.N., Karayani A.G., Arkhangelsky D.A. Improving the adaptive potential of young submariners in the conditions of the Far North. Marine Medical Journal named after D.P.Zuikhin, 2016, No. 1, pp. 40-46 (In Russ.)].

34. Relman D.A., Hamburg M.A., Choffnes E.R., Mack A. Global Climate Change and Extreme Weather Events: Understanding the Contributions to Infectious Disease Emergence: Workshop Summary. Forum on Global Health. Washington: National Academy of Sciences, 2008. 304 p.

35. Лучников Э.В.Цветкова М.М., Лучникова В.Н. Динамика иммунобиологических показателей у военнослужащих в процессе адаптации к изменяющимся условиям внешней среды // Mедико-биологические и социально-психологические проблемы безопасности в чрезвычайных ситуациях. 2017. №2. C. 83-91. [Luchnikov E.V., Tsvetkova M.M., Luchnikova V.N. Dynamics of immunobiological indicators in military personnel in the process of adaptation to changing environmental conditions // Medico-biological and socio-psychological problems of security in emergency situations. 2017. No. 2. P. 83-91 (In Russ.)].

36. Закревский Ю.Н., Шевченко А.Г., Архангельский Д.А., Перетечиков А.В., Панина Т.В. Медицинское обеспечение и лечебно-эвакуационные мероприятия в экстремальных условиях островов арктической зоны Российской Федерации // Медииина катастробб. 2017. № 3 (99). C. 5-9. [Zakrevsky Yu.N., Shevchenko A.G., Arkhangelsky D.A., Peretechikov A.V., Panina T.V. Medical support and medical evacuation measures in extreme conditions of the islands of the Arctic zone of the Russian Federation. Medicine of Catastrophes, 2017, No. 3 (99), pp. 5-9 (In Russ.)].

37. Anttonen H., Hiltunen E. Wind and cold have a joint effect on cooling // Barents. 1998. Vol. 1, No. 3. P. 90-92.

38. Jessen R. An assessment of human regulatory mechanisms of nonshivering thermogenesis // Acta anaesthesiol. 1980. Vol. 24, No. 3. P. 138-143.

39. Alwi I., Santoso T., Suyono S., Sutrisna B., Kresno S. B. The cut-off point of interleukin-6 level in acute coronary syndrome // Acta Med. Indones. 2007. Vol. 39, No. 4. P. 174-178.

40. O'Rourke R. Changes in the Arctic: Background and Issues for Congress. Congressional Research Service report, 2017. $109 \mathrm{p}$.

41. Рыбников В.Ю., Дубинский А.А., Бульгина В.Г. Индивидуально-психологические предикторы адаптации и дезадаптации специалистов экстремального профиля деятельности// Экология человека. № 3, 2017. С. 3-9. [Rybnikov V.Yu., Dubinsky A.A., Bulgina V.G. Individual psychological predictors of adaptation and disadaptation of specialists of extreme activity profile// Human ecology. No. 3, 2017. pp. 3-9].

42. Zuberbier T., Aberer W., Asero R. et al. The EAACI/GA2LEN/EDF/WAO Guideline for the Definition, Classification, Diagnosis and Management of Urticaria. The 2017 Revision and Update // Allergy. 2018. Vol. 73, No. 7, pp. 1393-1414. doi: 10.1111/all.13397.

43. Андреев В.П., Андриянов А.И., Закревский Ю.Н. Военно-медицинская характеристика питания военнослужащих в условиях их профессиональной деятельности в Арктике // Материаль научно-практической конфберениии "Сохранение здоровъя и санитарно-эпидемиологического благополучия в Арктике», С.-Петербург, 13-15 ноября 2019. СПб., 2019. С. 9-14. [Andreev V.P., Andriyanov A.I., Zakrevsky Yu.N. Military-medical characteristics of the nu- 
trition of military personnel in the conditions of their professional activity in the Arctic. Proceedings of the scientific and practical conference "Preservation of health and sanitary-epidemiological well-being in the Arctic», St. Petersburg, November 13-15. 2019. Saint Petersburg, 2019, pp. 9-14 (In Russ.)].

44. Артанас Л.И., Воевода М.И., Пузырев В.П. Арктическая медицина: Выводы ХХІ века // Научно-технические проблемъ освоения Арктики: Научная сессия общего собрания членов РАН. M.: Наука, 2014. C. 104-110. [Atanas L.I., Voevoda M.I., Puzyrev V.P. Arctic medicine: Conclusions of the XXI century. Scientific and technical problems of Arctic development: Scientific session of the General Meeting of Members of the Russian Academy of Sciences. Moscow: Publishing house Nauka, 2014, pp. 104-110 (In Russ.)].

45. Казначеев В.П. Клинические аспекты полярной медицинъ. М.: Медицина, 1986. 208 с. [Kaznacheev V.P. Clinical aspects of polar medicine. Moscow: Publishing house Medicine, 1986. 208 p. (In Russ.)].

46. Солонин Ю.Г., Бойко Е.Р. Медико-физиологические проблемы в Арктике // Известия Коми научного ијентра УроPAH. 2017. № 4 (32). C. 35-38. [Solonin Yu. G., Boyko E. R. Medico-physiological problems in the Arctic. News of the Komi Scientific Center. Ural Branch of the Russian Academy of Sciences, 2017, No. 4 (32), pp. 35-38 (In Russ.)].

47. Zacariassen E., Uleberg O., Røislien J. Helicopter Emergency Medical Services response times in Norway: Do they Matter? // Air Medical Journal. 2015. Vol. 34, No. 2. P. 98-103.

48. McLaughlin J.M., Johnson M.H., Kagan S.A., Baer S.L. Clinical and economic burden of community-acquired pneumonia in the Veterans Health Administration, 2011: a retrospective cohort study // Infection. 2015. Vol. 43, No. 6. P. 671-680.

49. Le Blanc J., Labrie A. Glycogen and nonspecific adaptation to cold // J. Appl. Phisiol. 1981. Vol. 51, No. 6. P. 1428-1432. 50. Maggiore C., Vazquez J., Guervil D., Ramani A., Jandourek A., Cole P., Friedland H.D. Ceftaroline fosamil for the treatment of community-acquired bacterial pneumonia in the intensive care unit // Ther. Clin. Risk. Manag. 2015. Vol. 11. P. 557-563.

\section{Авторский вклад в подготовку статьи:}

Поступила в редакцию/Received by the Editor: 29.09.2020 2.

Вклад в концепцию и план исследования - В.К.Жиров, Ю.Н.Закревский. Вклад в сбор данных - О.Б.Гонтаръ, Ю.Н.Закревский, А.А.Койгерова, П.А.Маурчева. Вклад в анализ данных и выводы - В.К.жиров, Ю.Н.Закревский, В.В.Мегорский. Вклад в подготовку рукописи - В.К.Жиров, Ю.Н.Закревский, О.Б.Гонтаръ.

\section{Сведения об авторах:}

Жиров Владимир Константинович - доктор биологических наук, член-корреспондент Российской академии наук, профессор, научный руководитель Полярно-альпийского ботанического сада-института имени Н.А.Аврорина Федерального исследовательского центра «Кольский научный центр Российской академии наук», и.о. научного руководителя Научного исследовательского центра медико-биологических проблем адаптации человека в Арктике Федерального исследовательского центра «Кольский научный центр Российской академии наук», советник Председателя федерального исследовательского центра «Кольский научный центр Российской академии наук»; 184209, г. Апатиты Мурманской обл., ул. Ферсмана, д. 14; 18a; 41a; e-mail: v_zhirov_1952@mail.ru;

Закревский Юрий Николаевич - доктор медицинских наук, профессор кафедры безопасности жизнедеятельности, руководитель направления обучения по специальности «Лечебное дело» федерального государственного бюджетного образовательного учреждения высшего образования «Мурманский арктический государственный университет»; 183038, Мурманск, ул. Капитана Егорова, д. 16; e-mail: zakrev.sever@bk.ru;

Гонтарь Оксана Борисовна - кандидат биологических наук, доцент, заместитель директора по научно-исследовательской деятельности Научного исследовательского центра медико-биологических проблем адаптации человека в Арктике Федерального исследовательского центра «Кольский научный центр Российской академии наук»; 184209, г. Апатиты Мурманской обл., ул. Ферсмана, д. 41a; e-mail: gontar_ob@mail.ru;

Мегорский Владимир Владимирович - кандидат медицинских наук, директор Научного исследовательского центра медико-биологических проблем адаптации человека в Арктике Федерального исследовательского центра «Кольский научный центр Российской академии наук»; 184209, г. Апатиты Мурманской обл., ул. Ферсмана, д. 41a; e-mail: v.megorskiy@ksc.ru; Койгерова Алена Алексеевна - младший научный сотрудник лаборатории медицинских и биологических технологий Федерального исследовательского центра «Кольский научный центр Российской академии наук»; 184209, г. Апатиты Мурманской обл., ул. Ферсмана, д. 41a; e-mail: kalichenko.alenk@mail.ru;

Маурчева Полина Александровна - младший научный сотрудник Полярно-альпийского ботанического сада-института им. Н.А.Аврорина Федерального исследовательского центра «Кольский научный центр Российской академии наук»; 184209, г. Апатиты Мурманской обл., ул. Ферсмана, д. 18a; e-mail: trushkova.polina@mail.ru. 